\title{
Inhibitory Effects of Balsamic Vinegar on LDL Oxidation and Lipid Accumulation in THP-1 Macrophages
}

\author{
Maki IIzUKA, Mariko TANI, Yoshimi Kishimoto, Emi SAITA, Miku ToYoZAKI \\ and Kazuo KONDO* \\ Institute of Environmental Science for Human Life, Ochanomizu University, 2-1-1, Otsuka, \\ Bunkyo-ku, Tokyo 112-8610, Japan \\ (Received May 26, 2010)
}

\begin{abstract}
Summary Oxidized low-density lipoprotein (LDL) is believed to contribute to atherosclerosis in part by being taken up into macrophages via scavenger receptors, thus accounting for foam cells. Balsamic vinegar is made from grapes and generally consumed in the Mediterranean region. In this study, we investigated the preventive effects of balsamic vinegar on LDL oxidation and foam cell formation. Balsamic vinegar had stronger 1,1-diphenyl-2-picrylhydrazyl (DPPH) radical scavenging abilities and higher polyphenol concentrations than rice vinegar. Balsamic vinegar dramatically inhibited LDL oxidation by azoradicals and endothelial cell-mediated oxidation in vitro. Further, we assessed the anti-oxidative effect against LDL after balsamic vinegar consumption in human subjects. Balsamic vinegar prolonged the LDL oxidation lag time and decreased lipid peroxide (LPO) and lyso-phosphatidylcholine (LPC) in LDL particles. We next examined the effect of balsamic vinegar on foam cell formation. Oil red $\mathrm{O}$ staining showed that balsamic vinegar inhibited oxidized LDL-induced foam cell formation in THP-1 macrophages. The concentrations of intracellular triglycerides and total cholesterols were reduced in the presence of balsamic vinegar. In addition, balsamic vinegar decreased the mRNA and protein expression level of scavenger receptors in THP-1 macrophages. These results showed that balsamic vinegar contained abundant polyphenols and inhibited LDL oxidation and oxidized LDL-induced foam cell formation by decreasing the expression of scavenger receptors.
\end{abstract}

Key Words balsamic vinegar, oxidation of LDL, foam cell formation, scavenger receptors, atherosclerosis

Balsamic vinegar is generally consumed in the Mediterranean region. The Mediterranean diet has been reported to be associated with a low rate of cardiovascular disease (CVD). A high-level of low-density lipoprotein (LDL) and the accumulation of oxidized LDL (oxLDL) have been linked to increased risks for developing atherosclerosis. Scavenger receptors are integral membrane proteins that bind to a wide variety of ligands, including modified and ox-LDL, lipoproteins, apoptotic cells and pathogens. Scavenger receptor-mediated recognition of ox-LDL by macrophages leads to the formation of foam cells and plaque. Therefore, reducing the process of LDL oxidation and lipoprotein uptake would presumably be a useful therapy for the prevention of atherogenic disease.

Balsamic vinegar is made from grapes which contain a large amount of various phenolic compounds in their skins, pulp, and seed as well as wine (1). Balsamic vinegar from Modena and Reggio Emilia in Italy is a unique product, produced from the alcoholic fermentation and acetic bioxidation of cooked and concentrated locally grown grape must. For balsamic vinegar the use of any extra additives is forbidden. The fermentation process is

\footnotetext{
*To whom correspondence should be addressed.
}

E-mail: kondo.kazuo@ocha.ac.jp performed in a series of barrels made of different woods and varying capacities for at least $12 \mathrm{y}$ (2).

Many reports have suggested that red wine may have an atheroprotective effect $(3,4)$, but balsamic vinegar has not yet been sufficiently investigated.

In the present study, we hypothesized that balsamic vinegar could inhibit LDL oxidation and foam cell formation, key early events involved in atherosclerosis.

\section{MATERIALS AND METHODS}

\section{Antioxidative activities of balsamic vinegar.}

Vinegar preparation: Balsamic vinegar and rice vinegar were purchased from the market (Ibaraki, Japan). We used rice vinegar, containing few phenolic compounds, as a negative control in this study. The vinegars were concentrated by nitrogen gas for $6 \mathrm{~h}$ until reduced one fifth.

Free radical-scavenging activity: The free radicalscavenging activity was determined using 1,1-diphenyl-2-picrylhydrazyl (DPPH) (Wako Pure Chemical Industries, Ltd., Osaka, Japan) as described previously (5). The volume of balsamic vinegar and rice vinegar required to cause a $50 \%$ decrease in the absorbance at $516 \mathrm{~nm}$ relative to the control was then calculated.

Determination of total polyphenol content: The total polyphenol content was determined by a Folin-Ciocal- 
teu assay as described previously (5). The total polyphenol content was expressed as a $(+)$-catechin equivalent.

Determination of LDL oxidizability (lag time assay): The LDL oxidizability was measured by lag time as described previously (6). LDL was isolated from plasma by single-spin density gradient ultracentrifugation $\left(417,000 \times g, 40 \mathrm{~min}, 4^{\circ} \mathrm{C}\right)$. The prepared LDL samples (final concentration of protein: $70 \mu \mathrm{g} / \mathrm{mL}$ ) were oxidized with or without $0.01 \%$ balsamic vinegar by 2,2 azobis4-methyoxy-2,4-dimethylvaleronitrile (V-70; AMVN-CH30) (Wako Pure Chemical Industries, Ltd.), which is an oxidative inducer. The formation of conjugated dienes was monitored at $234 \mathrm{~nm}$ with a DU 640 spectrophotometer (Beckman Coulter, Inc., CA, USA) at 4-min intervals at $37^{\circ} \mathrm{C}$.

Endothelial cell-mediated LDL oxidation: Human umbilical vein endothelial cells (HUVECs) (Lonza Walkersville, MD, USA) were cultured in M-199 medium (Invitrogen, Tokyo, Japan) supplemented with penicillin (100 IU/mL) and streptomycin $(100 \mu \mathrm{g} / \mathrm{mL})$, and $20 \%$ fetal bovine serum (FBS) (GIBCO, Tokyo, Japan), at $37^{\circ} \mathrm{C}$ and $5 \% \mathrm{CO}_{2}(7)$. HUVECs were incubated with LDL (100 $\mu \mathrm{g}$ protein $/ \mathrm{mL}$ ) in the presence or absence of balsamic vinegar in Ham's F10 medium (Lonza Walkersville). After $24 \mathrm{~h}$, the medium was analyzed for the extent of LDL oxidation as described below.

TBARS assay: Malondialdehyde (MDA) generated in a medium including LDL was measured using the thiobarbituric acid reactive substances (TBARS) assay as described by Buege and Aust $(8,9)$. The sample absorbance was measured at $535 \mathrm{~nm}$. Results are expressed as MDA-equivalent content (nanomoles of MDA per milligram of LDL protein) calculated using the extinction coefficient for MDA as previously described (9).

Agarose gel electrophoresis: The media including LDL were subjected to agarose gel electrophoresis performed at $400 \mathrm{~V}$ for $15 \mathrm{~min}$ using the rapid electrophoresis system (Helena Laboratories, Saitama, Japan). After electrophoresis, the plates were stained with Cho/Trig COMBO CH (Helena Laboratories).

Human subjects. Study subjects were 5 healthy female volunteers (age 24 1 y); none took any medications or special dietary additives. All were nonsmokers and in a good state of health. This study was approved by the Ethics Committee of Ochanomizu University and carried out in conformity with the Declaration of Helsinki (established in 1964 and revised in 2004). All subjects gave their informed consent to participate in the study. After an overnight fast, the study subjects consumed concentrated balsamic vinegar containing about $800 \mathrm{mg}$ polyphenol. Venous blood samples were taken at $0,0.5,1$ and $4 \mathrm{~h}$ after consumption; these samples then underwent isolation and preparation of LDL.

Lag time assay: The prepared LDL oxidizability was measured by lag time assay as described above.

LPC assay: Lyso-phosphatidylcholine (LPC) in LDL was measured using a commercially available reagent (AZWELL LPC Assay Kit, AZWELL, Osaka, Japan). The sample was measured spectrophotometrically at
$550 \mathrm{~nm}$.

LPO assay: Lipid peroxide (LPO) in LDL was measured using Determiner LPO (Kyowa Medex, Tokyo, Japan). The sample was measured spectrophotometrically at $675 \mathrm{~nm}$.

Effect of balsamic vinegar on foam cell formation.

Cell culture and differentiation of THP-1 cells: The human monocytic cell line THP-1 was obtained from the RIKEN Cell Bank (Ibaraki, Japan) and cultured in RPMI-1640 (Sigma-Aldrich, Tokyo, Japan) supplemented with penicillin (100 IU/mL) and streptomycin $\left(100 \mu \mathrm{g} / \mathrm{mL}\right.$ ), and $10 \% \mathrm{FBS}$, at $37^{\circ} \mathrm{C}$ and $5 \% \mathrm{CO}_{2}$. THP1 cells were treated with $0.01-0.1 \%$ balsamic vinegar for $6 \mathrm{~h}$. After incubation, THP-1 cells were stimulated with $320 \mathrm{nM}$ phorbol-12-myristate-13-acetate (PMA) (Sigma-Aldrich) for $72 \mathrm{~h}$ to induce differentiation into macrophages.

Oil red $\mathrm{O}$ staining and cellular lipid analysis: To oxidize LDL we incubated LDL with $10 \mu \mathrm{M} \mathrm{CuSO}_{4}$ at $37^{\circ} \mathrm{C}$ overnight. ox-LDL (20 mg cholesterol/dL) was added to PMA-differentiated THP-1 cells in fresh culture medium for $72 \mathrm{~h}$. After incubation, the cells were washed once in ice-cold PBS, followed by formaldehyde fixation (4\% in PBS) for $30 \mathrm{~min}$ at $4^{\circ} \mathrm{C}$. The fixed cells were rinsed with $60 \%$ isopropanol and stained using oil red $\mathrm{O}$ (Sigma-Aldrich) in isopropanol for $30 \mathrm{~min}$ at room temperature. The oil red O-stained lipids were morphologically evaluated by microscopy.

Intracellular triglycerides and cholesterols were measured by Determiner TG and Determiner TC (Kyowa Medex), respectively.

Real-time RT-PCR analysis: Total cellular RNA was extracted using TRIZOL Reagent (Invitrogen), and firststrand cDNA was synthesized from the total RNA $(0.2 \mu \mathrm{g})$ by using TaqMan ${ }^{\circledR}$ Reverse Transcription Reagents (Applied Biosystems, CA, USA). Real-time PCR was performed on an ABI 7300 cycler (Applied Biosystems) using SYBR green PCR mix. The results were expressed as a copy number ratio of the target mRNA to GAPDH mRNA. The primer sequences were as follows: for SR-A, forward 5'-AGGGCCCTCTTAAGATCAGG-3', reverse 5'-ACAACACGGGAACCAAAGTC-3'; for CD36, forward 5'-CAATTAAAAACCAAGTTGTCCCGA-3', reverse 5'-ATCACTTCCTGTGGATTTTGCA-3'; for LOX-1, forward 5'-ACAGATCTCAGCCCGGCAACAAGCA-3', reverse 5'-GGGAGACAGCGCCTCGGACTCTAAAT-3'; and for GAPDH, forward 5'-TGCACCACCAACTGCTTAGC3', reverse 5'-GGCATGGACTGTGGTCATGAG-3'.

Western blot analysis: After treatment, cells were washed with ice-cold PBS and lysed with protein extraction reagent (Pierce Biotechnology, IL, USA) containing $10 \mu \mathrm{g} / \mathrm{mL}$ leupeptin, $10 \mu \mathrm{g} / \mathrm{mL}$ aprotinin, and $1 \mathrm{mM}$ phenylmethylsulfonyl fluoride. Aliquots of cellular proteins were electrophoresed on 10\% SDS-polyacrylamide gel and transferred to an Immobilon-P membrane (Millipore, MA, USA). The membrane was allowed to react with SR-A, CD36 and LOX-1 (Santa Cruz, CA, USA), and detection of specific proteins was carried out by enhanced chemiluminescence. Loading differences were normalized using polyclonal actin antibodies. All 
signals were detected by LAS-4000 (Fujifilm, Tokyo, Japan). Densitometric analysis was performed using Multi Gauge version 3.0 (Fujifilm) to scan the signals.

Statistical analysis. Statistical analyses were performed using the StatView Version 5.0 software package (SAS Institute, Inc., NC, USA), and a value of $p<0.05$ was considered to indicate significance.

\section{RESULTS}

\section{Antioxidative activities of balsamic vinegar}

The antioxidant activities of balsamic vinegar and rice vinegar are shown in Table 1. For balsamic vinegar and rice vinegar it took $4.7 \pm 0.4 \mu \mathrm{L}$ and $23.1 \pm 2.3 \mu \mathrm{L}$ to scavenge $50 \%$ of the DPPH radicals, respectively. The polyphenol concentration of balsamic vinegar was $2.1 \pm 0.1 \mathrm{mg} / \mathrm{mL}$, whereas that of rice vinegar was $0.5 \pm 0.1 \mathrm{mg} / \mathrm{mL}$.

Inhibitory effect of balsamic vinegar on LDL oxidation in vitro

To evaluate the antioxidant effects of balsamic vinegar on LDL oxidation, we carried out the LDL lag time assay. As shown in Fig. 1, balsamic vinegar significantly prolonged LDL oxidation lag time $(32 \pm 6.7 \mathrm{~min}$ to $59 \pm 4.2 \min (p<0.001))$.

We also examined the inhibitory effect of balsamic vinegar on endothelial cell-mediated LDL oxidation. Balsamic vinegar significantly reduced TBARS formation in HUVEC-mediated LDL oxidation (Fig. 2a). Furthermore, we evaluated the change in the surface charge of LDL by agarose gel electrophoresis. The oxidation of LDL can be monitored by comparing the relative electrophoresis mobility of unmodified and modified LDL. Balsamic vinegar significantly suppressed LDL modification compared to native LDL in HUVEC-mediated LDL oxidation $(p<0.001)$ (Fig. 2b). Balsamic vinegar did not affect cell viability under our experimental conditions (data not shown).

Inhibitory effect of balsamic vinegar on LDL oxidation in human subjects

Five subjects consumed balsamic vinegar containing about $800 \mathrm{mg}$ of polyphenol. As shown in Fig. 3a, the lag time was prolonged 1.3 times at $1 \mathrm{~h}$ compared with the baseline. The consumption of balsamic vinegar decreased LPO product at $1 \mathrm{~h}$ (Fig. 3b), and significantly decreased LPC products at each time point (Fig. 3c). These results showed that balsamic vinegar could suppress LDL oxidation in vitro and in human subjects.

Effect of balsamic vinegar on foam cell formation

We first checked the cytotoxity of balsamic vinegar in THP-1 macrophages by MTT assay. Balsamic vinegar did not affect cell viability under our experimental conditions (data not shown).

Table 1. Antioxidant activity of balsamic vinegar.

\begin{tabular}{llc}
\hline & $\begin{array}{c}\text { Polyphenol } \\
(\mathrm{mg} / \mathrm{mL})\end{array}$ & $\begin{array}{c}\mathrm{IC}_{50} \text { value of vinegar } \\
\text { for DPPH scavenge }\end{array}$ \\
\hline Balsamic vinegar & $2.1 \pm 0.1^{* * *}$ & $4.7 \pm 0.4^{* * *}$ \\
Rice vinegar & $0.5 \pm 0.1$ & $23.1 \pm 2.3$ \\
\hline
\end{tabular}

Data are mean \pm SD. $n=5 .{ }^{* * *} p<0.001$ vs. rice vinegar by Fischer's PLSD test after ANOVA.

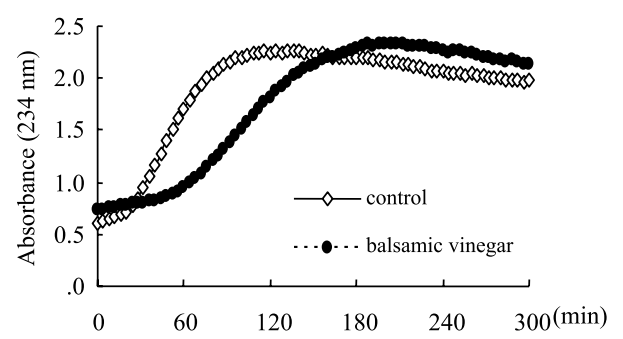

Fig. 1. Effect of balsamic vinegar on LDL oxidation lag time. LDL (70 $\mu \mathrm{g} / \mathrm{mL}$ protein) was incubated with balsamic vinegar, and then incubated in the presence of $\mathrm{V}$ 70 (final concentration $400 \mu \mathrm{M}$ ) at $37^{\circ} \mathrm{C}$. The formation of conjugated diene was determined by monitoring changes in absorbance at $234 \mathrm{~nm}$ every $4 \mathrm{~min}$. Representative data from three independent experiments are shown. a

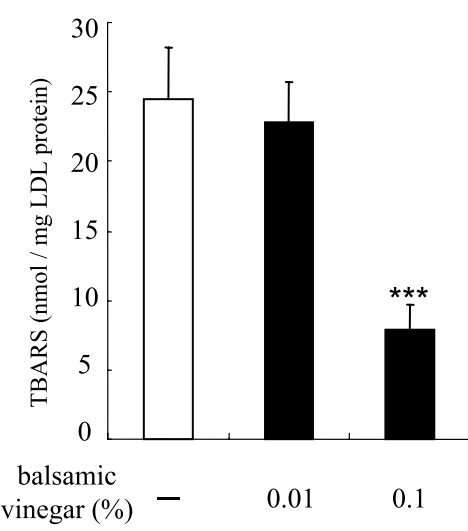

b

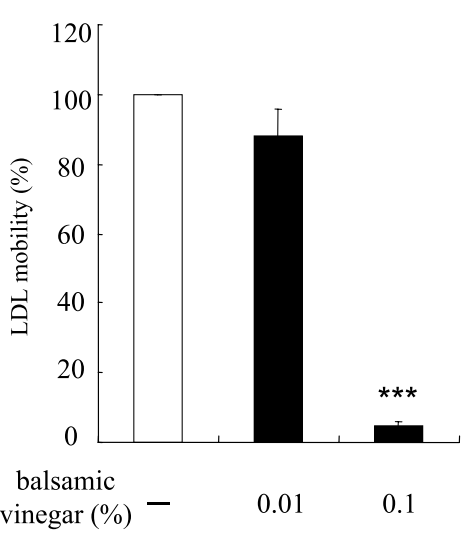

Fig. 2. Effect of balsamic vinegar on HUVEC-mediated LDL oxidation. HUVECs were co-incubated with $0.1 \%$ or $0.01 \%$ balsamic vinegar and LDL for $24 \mathrm{~h}$ in Ham's F-10 medium. (a) The lipid oxidation products were assessed by the TBARS assay. (b) The LDL mobility was measured by agarose gel electrophoresis. Data are mean \pm SD. $n=5$. ${ }^{* * *} p<0.001$ vs. balsamic vinegar (-) by Fischer's PLSD test after ANOVA. 

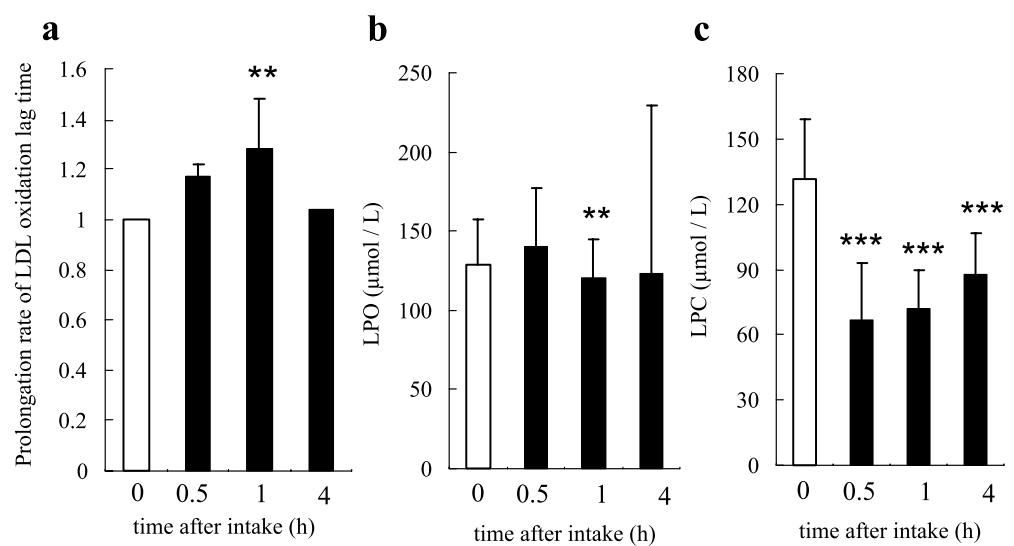

Fig. 3. Effect of balsamic vinegar consumption on oxidation against LDL in healthy subjects. After overnight fasting, 5 healthy volunteers ingested the balsamic vinegar containg $800 \mathrm{mg}$ polyphenol. Blood was sampled before intake and 0.5 , $1,4 \mathrm{~h}$ after intake. We measured LDL oxidizability in the presence of V-70 (final concentration $200 \mu \mathrm{M}$ ) by lag time assay (a), LPC assay (b) and LPO assay (c). Data are mean \pm SE. $n=5{ }^{* * *} p<0.001,{ }^{* *} p<0.01$ vs. 0 h by Fischer's PLSD test after ANOVA.
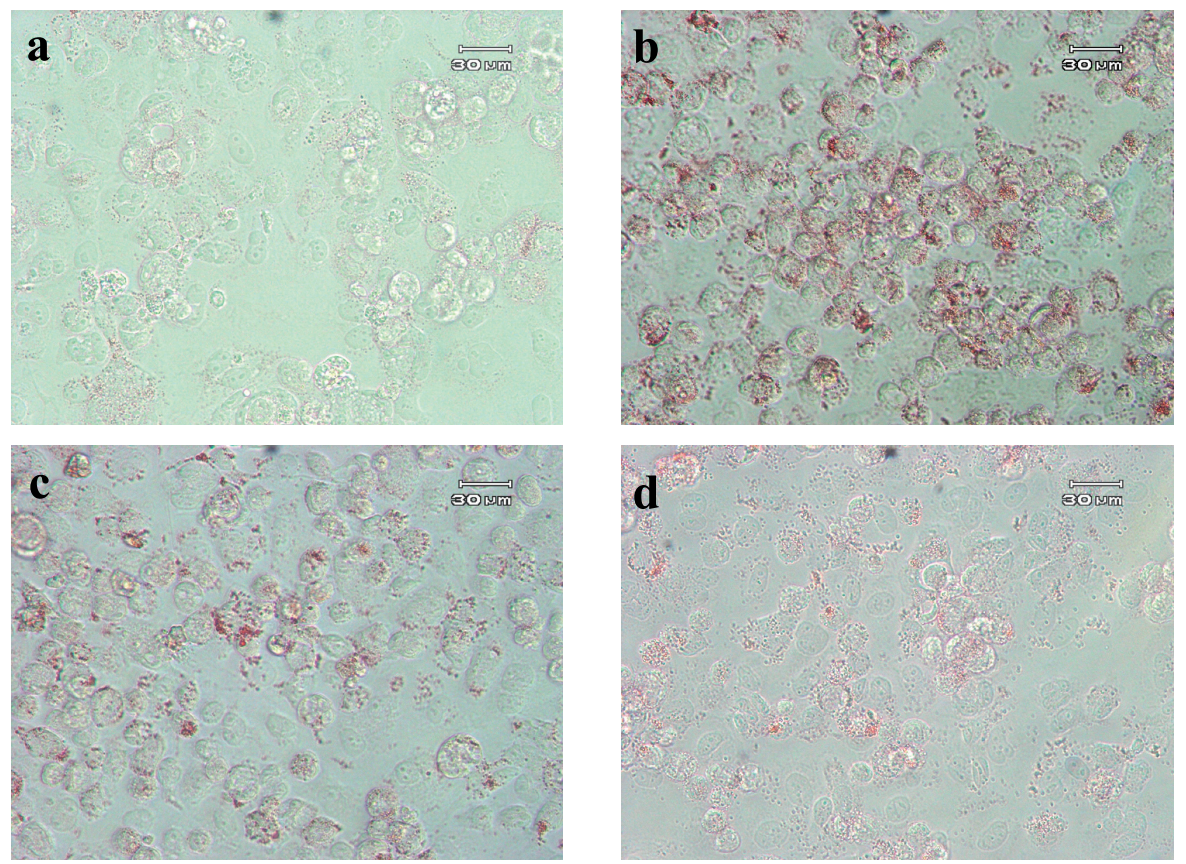

e
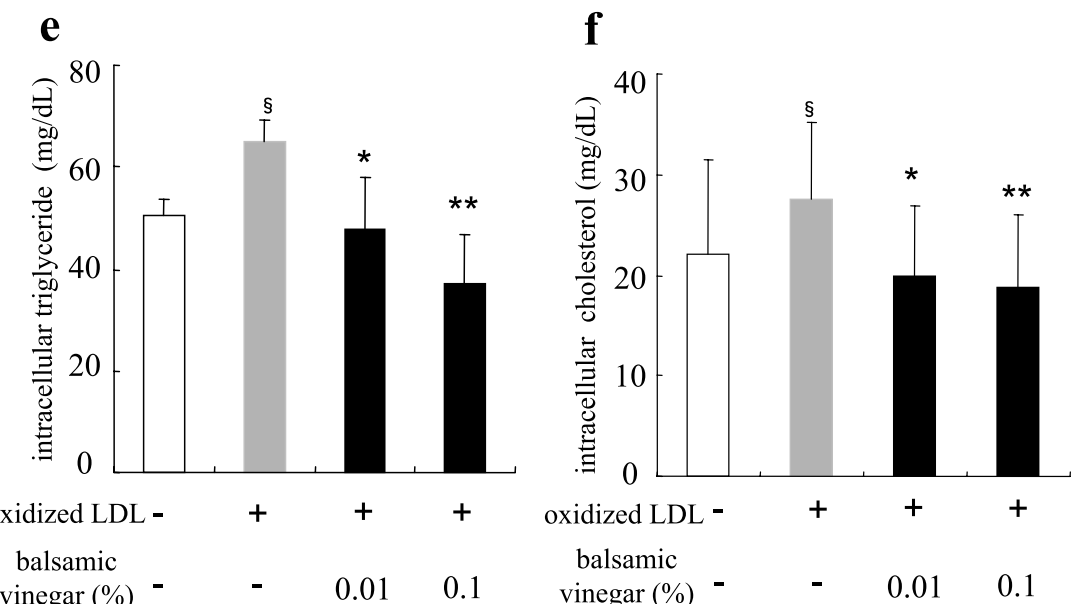

Fig. 4. Inhibitory effect of balsamic vinegar on lipid accumulation in THP-1 macrophages. THP-1 cells were pretreated with/without balsamic vinegar at each concentration for $6 \mathrm{~h}$. After differentiation, THP-1 macrophages were incubated with ox-LDL for $72 \mathrm{~h}$. Then the cells were stained with oil red $\mathrm{O}$ and observed under the microscope ((a) no treatment, (b) ox-LDL, (c) ox-LDL $+0.01 \%$ balsamic vinegar, (d) ox-LDL $+0.1 \%$ balsamic vinegar). We measured the concentration of intracellar triglycerides (e) and cholesterols (f) in ox-LDL-induced foam cells. Data are mean \pm SD. $n=4 .{ }^{\S} p<0.05$ vs. oxLDL $(-),{ }^{*} p<0.05,{ }^{* *} p<0.01$ vs. ox-LDL $(+)$ by Fischer's PLSD test after ANOVA. 
$\mathbf{a}$
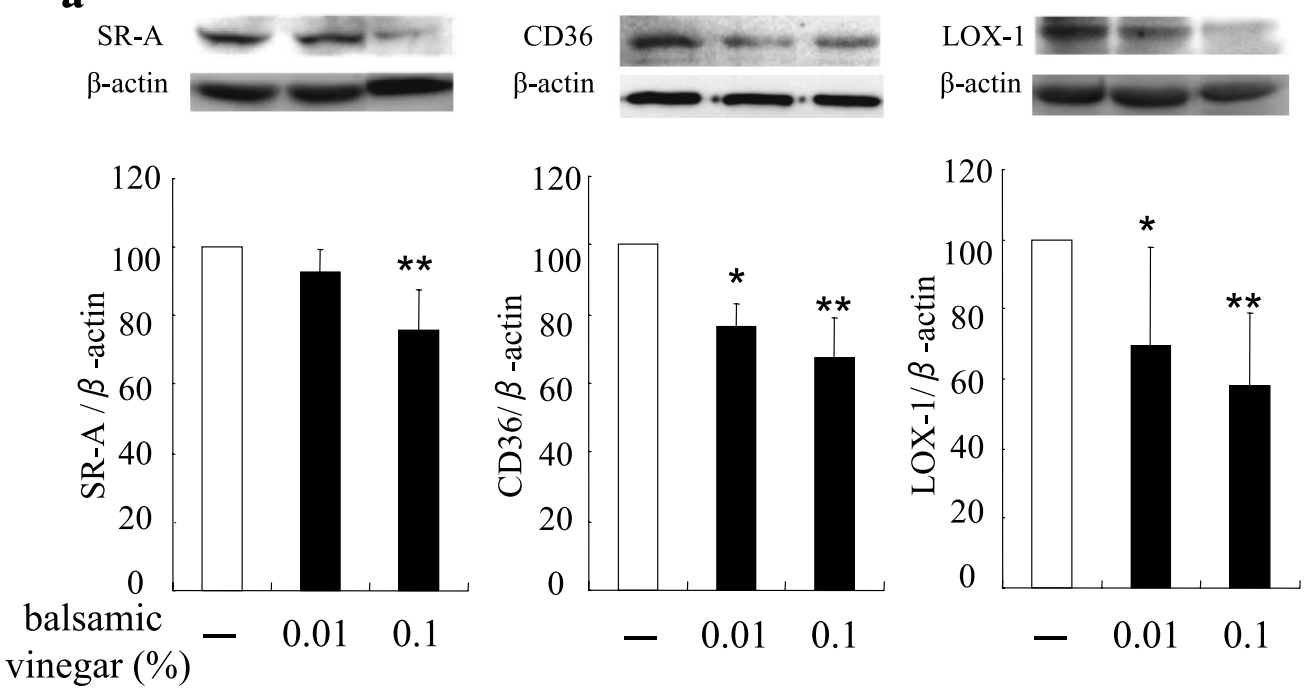

b
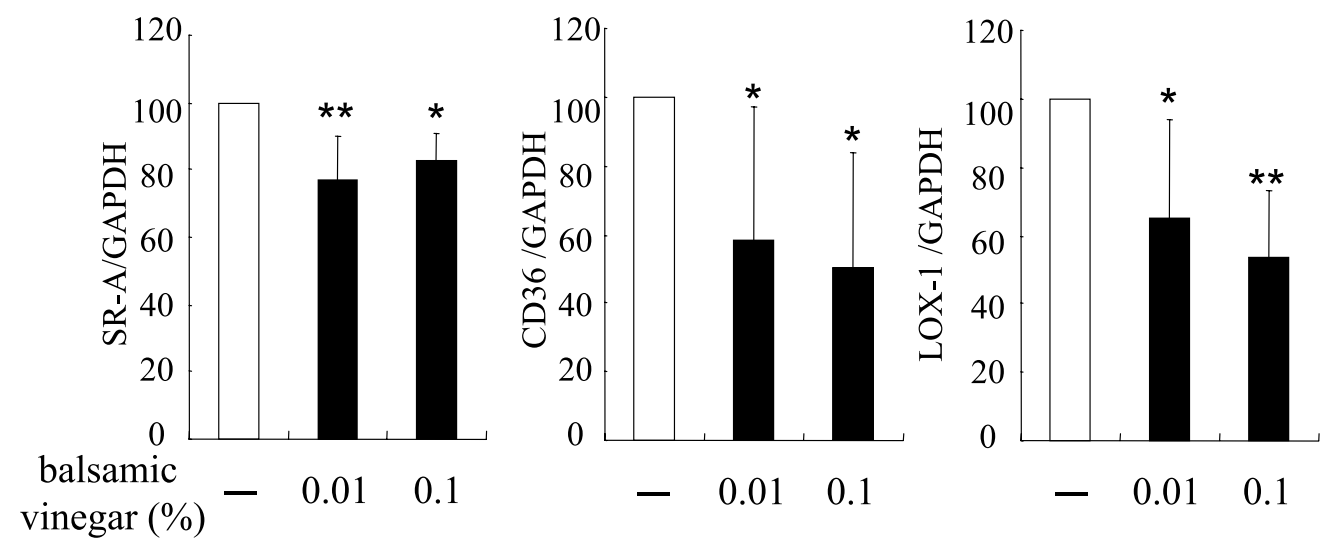

Fig. 5. Effect of balsamic vinegar on expression of the scavenger receptors in THP-1 macrophages. THP-1 cells were pretreated with/without balsamic vinegar at each concentration for $6 \mathrm{~h}$, and then allowed to differentiate into macrophage by PMA. We measured the expression of scavenger receptors (SR-A, CD36 and LOX-1) in protein level (a) and mRNA level (b). Data are mean \pm SD. $n=5 .{ }^{* * *} p<0.001,{ }^{* *} p<0.01,{ }^{*} p<0.05$ vs. balsamic vinegar $(-)$ by Fischer's PLSD test after ANOVA.

Oil red O staining showed that ox-LDL increased lipid accumulation (Fig. 4b), whereas balsamic vinegar inhibited lipid accumulation in THP-1 macrophages (Fig. 4c, d). The concentrations of intracellular triglycerides and cholesterols were significantly reduced in the presence of balsamic vinegar (Fig. 4e, f). Next, we examined whether balsamic vinegar suppressed the expression of scavenger receptors in THP-1 macrophages. Balsamic vinegar significantly decreased the protein expression of scavenger receptors at $0.01-0.1 \%$ in THP1 macrophages (Fig. 5a). In addition, balsamic vinegar decreased the mRNA expression levels in a dose-dependent manner, indicating that balsamic vinegar inhibited scavenger receptors expression by directly modulating gene transcription (Fig. 5b).

\section{DISCUSSION}

Ox-LDL is involved in foam cell formation and has been recognized as playing an important role in the initiation and progression of atherosclerosis. In this study we demonstrated that balsamic vinegar reduced LDL oxidizability both in vitro and in human subjects, and inhibited lipid accumulation by decreasing the expression of SR-A, CD36 and LOX-1 in THP-1 macrophages.

We first checked the radical scavenging activity of balsamic vinegar compared with that of rice vinegar, which is one of the most common traditional vinegars in Japan. Balsamic vinegar had 4-fold higher polyphenol concentration and showed a remarkably higher DPPH radical-scavenging activity than rice vinegar. It has been already demonstrated that traditional balsamic vinegar contains several polyphenols such as tannins (10), flavonoids and phenolic acids. Among polyphenols, a progressive decrease in catechins and an increase in polymeric tannin have been observed during balsamic vinegar aging (11).

We next evaluated the antioxidant activity of balsamic vinegar against LDL. Ox-LDL is produced in vivo by at least two mechanisms: (1) autoxidation in the presence of a free radical; (2) endothelial cell-mediated 
oxidation. Balsamic vinegar significantly prolonged the LDL oxidation lag time using V-70 to oxidize LDL in vitro, indicating that it could prevent free radicalinduced lipid peroxidation in LDL. To examine the effect of balsamic vinegar on endothelial cell-mediated LDL oxidation, we incubated LDL with HUVEC in Ham's F10 medium, containing $\mathrm{Fe}^{2+}$ (12) in the presence or absence of balsamic vinegar. We confirmed that TBARS production was increased in endothelial cell-mediated LDL oxidation, which was decreased by balsamic vinegar treatment. Balsamic vinegar also inhibited the increase of negative charges in LDL particles, indicating a role for prevention of apolipoprotein B100 modification in LDL. A number of different enzyme systems such as lipoxygenases, myeloperoxidase, NADPH oxidase, and other peroxidases have been shown to have the potential to contribute to the oxidation of LDL. Some polyphenols such as catechin (13) or quercetin (14) have been reported to inhibit these enzyme activities, suggesting that the polyphenols in balsamic vinegar might affect the enzymes activity and inhibit LDL oxidation in endothelial cells.

To identify the contribution of balsamic vinegar to protecting against LDL oxidation, we conducted additional experiments in human subjects. LDL oxidizability was significantly reduced at $1 \mathrm{~h}$ after balsamic vinegar consumption. As previously reported, catechin levels in blood were elevated at $1 \mathrm{~h}$ after red wine intake in humans (15). We also reported that the consumption of the grape skin, which contained anthocyanidins and resveratrol, showed an inhibitory effect on LDL oxidation after $1 \mathrm{~h}(6)$. Our results and previous reports indicated that balsamic vinegar consumption may be associated with an increase in plasma polyphenol levels and the inhibition of LDL oxidation.

Ox-LDL accelerates the infiltration of monocytes into the intima, which results in the stagnation of monocyte-derived macrophages. The macrophages then take up ox-LDL and are transformed into foam cells, which develop into fatty streaks. We used THP-1 cells that represent a well-known model of human macrophages (16), widely used in studies of foam cell formation (1719). In this study, we showed that balsamic vinegar inhibited lipid accumulation and SR-A, CD36 and LOX1 expression in THP-1 macrophages. The expression of scavenger receptors has been known to be regulated by transcription factors, such as nuclear factor kappa B $(\mathrm{NF} \kappa \mathrm{B})$ and peroxisome proliferator-activated receptor gamma (PPAR $\gamma)$ (20). Recent studies have demonstrated that some antioxidants, such as citrus flavonoids $(21,22)$ and astaxanthin (23), suppressed the expression of SR-A, CD 36 and LOX-1. Thus, we thought that the antioxidant property of balsamic vinegar might account for its inhibitory effect on SR-A, CD36 and LOX-1 expression.

Furthermore, macrophage-derived foam cells play a crucial role in inflammation via production of proinflammatory mediators such as inflammatory cytokines (24) and matrix metalloproteinases (MMP) related to plaque instability (25). Our findings sug- gested that balsamic vinegar might be useful for regulating inflammation from foam cells as well as inhibiting foam cell formation.

In conclusion, balsamic vinegar inhibited LDL oxidation and ox-LDL-induced foam cell formation by decreasing the expression of scavenger receptors in macrophages. Our findings suggest that balsamic vinegar can be effective to regulate risk factors of atherosclerosis progression.

\section{Acknowledgments}

This study was supported in part by a Grant-in-Aid (20300244 to K.K.) from the Japan Society for the Promotion of Science. Y.K. is supported by research fellowships of the Japan Society for the Promotion of Science for young scientists. We thank all members of the Kondo Laboratory for critical discussion.

\section{REFERENCES}

1) Glass CK, Witztum JL. 2001. Atherosclerosis. The road ahead. Cell 104: 503-516.

2) Cascieri MA. 2002. The potential for novel anti-inflammatory therapies for coronary artery disease. Nat Rev Drug Discov 1: 122-130.

3) Kondo K, Matsumoto A, Kurata H, Tanahashi H, Koda H, Amachi T, Itakura H. 1994. Inhibition of oxidation of low-density lipoprotein with red wine. Lancet 344: 1152.

4) Lefevre J, Michaud SE, Haddad P, Dussault S, Menard C, Groleau J, Turgeon J, Rivard A. 2007. Moderate consumption of red wine (cabernet sauvignon) improves ischemia-induced neovascularization in apoe-deficient mice: Effect on endothelial progenitor cells and nitric oxide. FASEB J 21: 3845-3852.

5) Hirano R, Kondo K, Iwamoto T, Igarashi O, Itakura H. 1997. Effects of antioxidants on the oxidative susceptibility of low-density lipoprotein. J Nutr Sci Vitaminol 43: 435-444.

6) Kamiyama M, Kishimoto Y, Tani M, Ando K, Utsunomiya K, Kondo K. 2009. Inhibition of low-density lipoprotein oxidation by nagano purple grape (vitis vinifera $\times$ vitis labrusca). J Nutr Sci Vitaminol 55: 471478.

7) Ronco AM, Garrido A, Llanos MN, Guerrero-Bosagna C, Tamayo D, Hirsch S. 2005. Effect of homocysteine, folates, and cobalamin on endothelial cell- and copperinduced LDL oxidation. Lipids 40: 259-264.

8) Buege JA, Aust SD. 1978. Microsomal lipid peroxidation. Methods Enzymol 52: 302-310.

9) Bors W, Saran M. 1987. Radical scavenging by flavonoid antioxidants. Free Radic Res Commun 2: 289294.

10) Tagliazucchi M, Calvo EJ, Szleifer I. 2008. Redox and acid-base coupling in ultrathin polyelectrolyte films. Langmuir 24: 2869-2877.

11) Verzelloni E, Tagliazucchi D, Conte A. 2010. Changes in major antioxidant compounds during aging of traditional balsamic vinegar. J Food Biochem 32: 152-171.

12) Yoshida H, Ishikawa T, Hosoai H, Suzukawa M, Ayaori M, Hisada T, Sawada S, Yonemura A, Higashi K, Ito T, Nakajima K, Yamashita T, Tomiyasu K, Nishiwaki M, Ohsuzu F, Nakamura H. 1999. Inhibitory effect of tea flavonoids on the ability of cells to oxidize low density 
lipoprotein. Biochem Pharmacol 58: 1695-1703.

13) Schewe T, Sadik C, Klotz LO, Yoshimoto T, Kuhn H, Sies H. 2001. Polyphenols of cocoa: Inhibition of mammalian 15-lipoxygenase. Biol Chem 382: 1687-1696.

14) Sadik CD, Sies H, Schewe T. 2003. Inhibition of 15lipoxygenases by flavonoids: Structure-activity relations and mode of action. Biochem Pharmacol 65: 773-781.

15) Bell JR, Donovan JL, Wong R, Waterhouse AL, German JB, Walzem RL, Kasim-Karakas SE. 2000. (+)-Catechin in human plasma after ingestion of a single serving of reconstituted red wine. Am J Clin Nutr 71: 103-108.

16) Auwerx J. 1991. The human leukemia cell line, THP-1: A multifacetted model for the study of monocyte-macrophage differentiation. Experientia 47: 22-31.

17) Llaverias G, Jove M, Vazquez-Carrera M, Sanchez RM, Diaz C, Hernandez G, Laguna JC, Alegret M. 2002. Avasimibe and atorvastatin synergistically reduce cholesteryl ester content in thp-1 macrophages. Eur J Pharmacol 451: 11-17.

18) Fu Y, Luo N, Lopes-Virella MF, Garvey WT. 2002. The adipocyte lipid binding protein (ALBP/aP2) gene facilitates foam cell formation in human THP-1 macrophages. Atherosclerosis 165: 259-269.

19) Argmann CA, Sawyez CG, McNeil CJ, Hegele RA, Huff MW. 2003. Activation of peroxisome proliferator-activated receptor gamma and retinoid $X$ receptor results in net depletion of cellular cholesteryl esters in macrophages exposed to oxidized lipoproteins. Arterioscler
Thromb Vasc Biol 23: 475-482.

20) Nagy L, Tontonoz P, Alvarez JG, Chen H, Evans RM. 1998. Oxidized LDL regulates macrophage gene expression through ligand activation of PPARgamma. Cell 93: 229-240.

21) Eguchi A, Murakami A, Li S, Ho CT, Ohigashi H. 2007. Suppressive effects of demethylated metabolites of nobiletin on phorbol ester-induced expression of scavenger receptor genes in THP-1 human monocytic cells. Biofactors 31: 107-116.

22) Eguchi A, Murakami A, Ohigashi H. 2006. Nobiletin, a citrus flavonoid, suppresses phorbol ester-induced expression of multiple scavenger receptor genes in THP1 human monocytic cells. FEBS Lett 580: 3321-3328.

23) Kishimoto Y, Tani M, Uto-Kondo H, Iizuka M, Saita E, Sone H, Kurata H, Kondo K. 2010. Astaxanthin suppresses scavenger receptor expression and matrix metalloproteinase activity in macrophages. Eur J Nutr 49: 119-126.

24) Jung WJ, Sung MK. 2004. Effects of major dietary antioxidants on inflammatory markers of raw 264.7 macrophages. Biofactors 21: 113-117.

25) Galis ZS, Sukhova GK, Lark MW, Libby P. 1994. Increased expression of matrix metalloproteinases and matrix degrading activity in vulnerable regions of human atherosclerotic plaques. J Clin Invest 94: 24932503. 